\section{Efecto de la terapia con probióticos/ prebióticos sobre la reconstitución del tejido linfoide asociado a la mucosa gastrointestinal durante la infección por el virus de la inmunodeficiencia humana-1}

\author{
MANUEL G. FERIA ${ }^{1, a}$, NATALIA A. TABORDA ${ }^{1,2, b}$, \\ JUAN C. HERNANDEZ ${ }^{3, \mathrm{~b}}$, MARÍA T. RUGELES ${ }^{1, \mathrm{c}}$
}

\section{Effects of prebiotics and probiotics on gastrointestinal tract lymphoid tissue in HIV infected patients}

HIV infection induces alterations in almost all immune cell populations, mainly in CD4+ T cells, leading to the development of opportunistic infections. The gut-associated lymphoid tissue (GALT) constitutes the most important site for viral replication, because the main target cells, memory $T$-cells, reside in this tissue. It is currently known that alterations in GALT are critical during the course of the infection, as HIV-1 induces loss of tissue integrity and promotes translocation of microbial products from the intestinal lumen to the systemic circulation, leading to a persistent immune activation state and immune exhaustion. Although antiretroviral treatment decreases viral load and substantially improves the prognosis of the infection, the alterations in GALT remains, having a great impact on the ability to establish effective immune responses. This emphasizes the importance of developing new therapeutic alternatives that may promote structural and functional integrity of this tissue. In this regard, therapy with probiotics/prebiotics has beneficial effects in GALT, mainly in syndromes characterized by intestinal dysbiosis, including the HIV-1 infection. In these patients, the consumption of probiotics/prebiotics decreased microbial products in plasma and CD4+ T cell activation, increased CD4+ T cell frequency, in particular Th17, and improved the intestinal flora. In this review, the most important findings on the potential impact of the probiotics/prebiotics therapy are discussed.

(Rev Med Chile 2017; 145: 219-229)

Key words: HIV-1; Gastrointestinal Microbiome; Prebiotics; Probiotics.

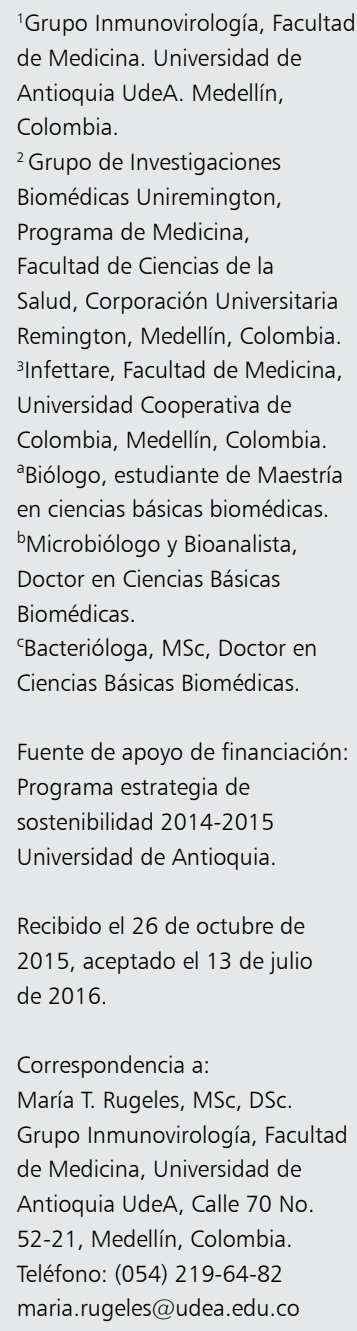

Fuente de apoyo de financiación: Programa estrategia de sostenibilidad 2014-2015

Universidad de Antioquia.

Recibido el 26 de octubre de 2015, aceptado el 13 de julio de 2016.

\section{Correspondencia a:}

María T. Rugeles, MSc, DSc. Grupo Inmunovirología, Facultad de Medicina, Universidad de Antioquia UdeA, Calle 70 No. 52-21, Medellín, Colombia. Teléfono: (054) 219-64-82 maria.rugeles@udea.edu.co

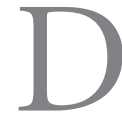
esde su aparición en 1981, la infección por el virus de la inmunodeficiencia humana tipo 1 (VIH-1) ha causado más de 39 millones de muertes. Para el año 2014, se reportaron 36,9 millones de personas infectadas y una incidencia de 2,0 millones de infecciones en el mundo ${ }^{1}$.

Durante la exposición al VIH-1, la interacción entre virus y sistema inmune es un evento crítico que determina su eliminación o diseminación ${ }^{2}$. 
En este último caso, la respuesta inmune determina la magnitud de la replicación viral y el establecimiento del "set point viral" que influirá en las alteraciones inmunes que se desarrollen durante la fase crónica ${ }^{3}$. La fase aguda se caracteriza por un incremento exponencial de la carga viral y una eliminación masiva de linfocitos $\mathrm{T}$ (LT) $\mathrm{CD} 4^{+}$, particularmente en el tejido linfoide asociado a la mucosa gastrointestinal (GALT), independientemente de la vía de infección ${ }^{4}$. A pesar de la respuesta inmune, el control viral se da parcialmente, debido al alto grado de replicación viral, a los mecanismos de evasión inmune y al establecimiento de reservorios virales ${ }^{4}$.

La eliminación de LT-CD4 ${ }^{+}$y de enterocitos en GALT induce una pérdida de la integridad de la mucosa, favoreciendo la translocación de productos microbianos desde el lumen intestinal hacia la circulación sistémica, lo que determina el desarrollo del estado de hiperactivación inmune ${ }^{5}$, que favorece el agotamiento inmunológico y el desarrollo del síndrome de inmunodeficiencia adquirida (SIDA) $)^{2,4}$.

La instauración de la terapia antirretroviral altamente activa (TAR) suprime la carga viral y promueve la recuperación de $\mathrm{LT}-\mathrm{CD} 4^{+}$; no obstante, no logra normalizar la estructura de los órganos linfoides, ni los parámetros funcionales e inmunológicos, incluyendo la activación inmune ${ }^{6}$. Lo anterior resalta la importancia de buscar alternativas terapéuticas que puedan ser suministradas, en forma simultánea con la TAR, e incluso previo a esta, para promover la recuperación del GALT.

La terapia con probióticos/prebióticos, recientemente, ha sido utilizada como estrategia terapéutica junto con la TAR, y ha demostrado tener efectos positivos en el estado clínico de los pacientes infectados con el virus ${ }^{7,8}$. Los probióticos son microorganismos vivos, principalmente bacterias ${ }^{9}$, mientras que los prebióticos son ingredientes alimenticios no digeribles que promueven el crecimiento de bacterias benéficas, modificando la actividad y composición de la microbiota intestinal ${ }^{10}$. Particularmente, se ha demostrado que la administración simultanea de prebióticos y probióticos, conocida como terapia simbiótica, también induce efectos benéficos en pacientes infectados con VIH-1 en TAR ${ }^{11}$.

Estos hallazgos sugieren que el consumo de probióticos/prebióticos podría favorecer la reconstitución de la mucosa gastrointestinal, retrasando la progresión a SIDA. Esta revisión tiene como objetivo recopilar los hallazgos más recientes relacionados con la importancia de los probióticos/prebióticos como terapia en la restauración inmune del GALT durante la infección por el VIH-1.

\section{Patogénesis de la infección por el VIH-1}

La fase aguda se caracteriza por una carga viral elevada y una eliminación masiva de LT-CD4 ${ }^{+}$ $\mathrm{CCR}^{+}$de memoria efectora, especialmente en GALT, donde se encuentran más del $60 \%$ de estas células ${ }^{12}$. Las partículas virales libres o células infectadas ingresan a la mucosa por transcitosis o transmigración, adherencia a las células dendríticas y paso directo a través de brechas epiteliales ${ }^{12}$. La muerte de los LT-CD4 ${ }^{+}$se da por efectos directos del virus, en el caso de las células infectadas, mientras que células no infectadas mueren por apoptosis inducida por activación o por piroptosis inducida por proteínas virales solubles ${ }^{12,13}$.

Las alteraciones de los linfocitos Th17, que son preferencialmente infectados y eliminados durante la infección por el VIH-1 debido a su alta expresión del correceptor CCR5 y su perfil de memoria efectora, determina en gran medida el daño del GALT ${ }^{12}$. En condiciones fisiológicas estas células promueven la integridad de la mucosa, produciendo IL-17, que induce proliferación de células epiteliales, expresión de defensinas, reclutamiento de neutrófilos y producción de proteínas que fortalecen las uniones entre células epiteliales $^{12}$.

La infección por el VIH-1 desencadena mecanismos efectores de la respuesta inmune que ejercen un control parcial de la infección, pero no impiden el daño estructural o anatómico del GALT, lo que resulta en el paso de productos microbianos del lumen intestinal hacia los nódulos linfoides mesentéricos y finalmente hacia la circulación sistémica, llevando a un aumento en los niveles de lipopolisacáridos (LPS), ARN ribosomal 16 s bacterial (16s ARNr) y CD14 soluble (CD14s) en plasma ${ }^{5,7,14}$. Este fenómeno desencadena la hiperactivación inmunológica generalizada, principal mecanismo patogénico de la infección ${ }^{15}$, que se caracteriza por una expansión policlonal de LT y $B$ activados, incremento en el recambio de LT $y$ altos niveles de citoquinas proinflamatorias ${ }^{14,15}$. 


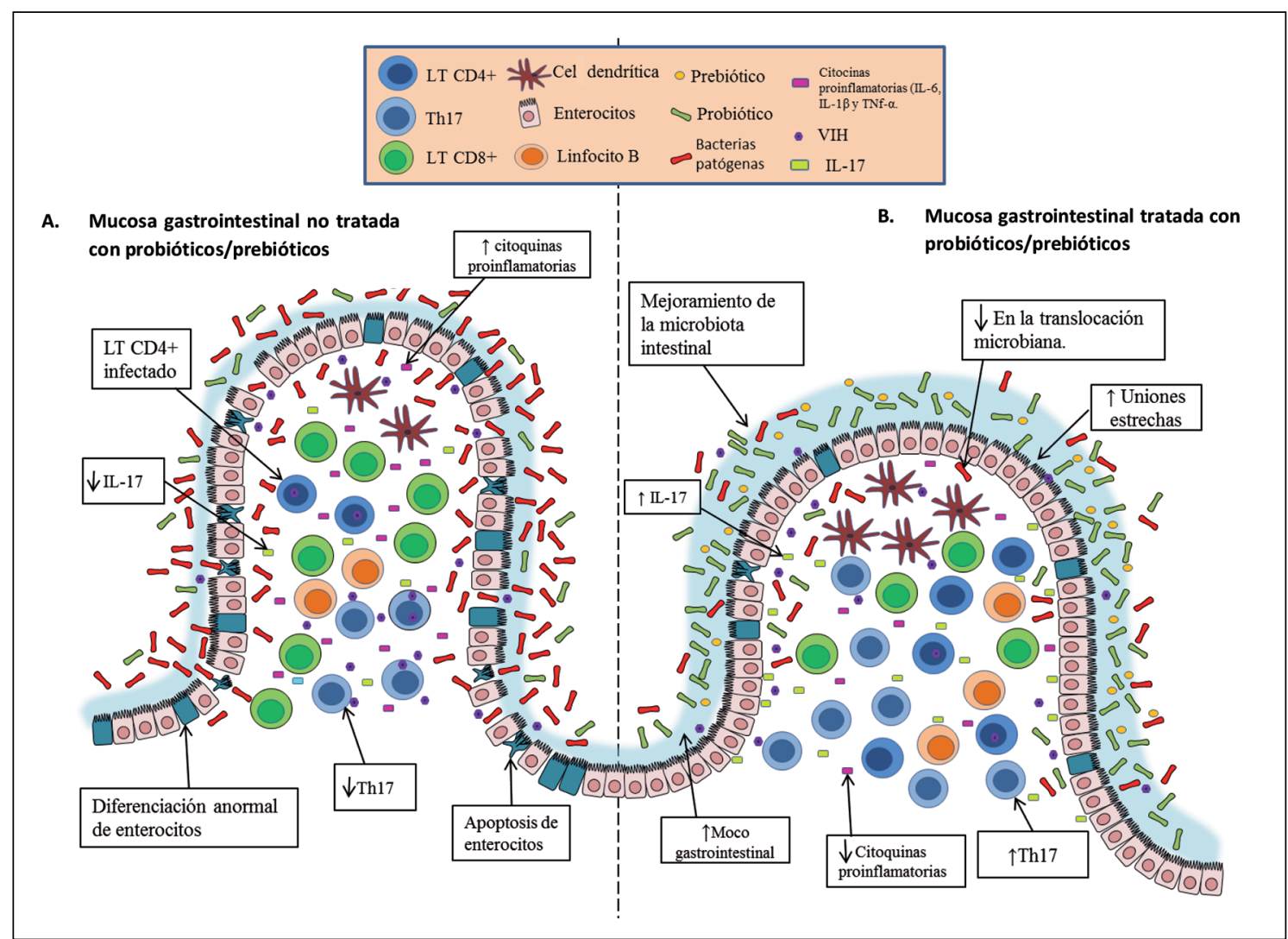

Figura 1. Efectos de la terapia con probióticos/prebióticos en la mucosa gastrointestinal. Se muestra una mucosa de un paciente infectado con $\mathrm{VIH}-1$. A. Mucosa gastrointestinal no tratada con probióticos/prebióticos: se observa una disbiosis de la microbiota intestinal, con una gran cantidad de bacterias patógenas, que alteran la homeostasis inmunológica. Igualmente, la replicación del VIH-1 en la mucosa gastrointestinal induce una eliminación masiva de linfocitos T CD4+, específicamente Th17, que junto con la eliminación de enterocitos, por apoptosis o diferenciación anormal, lleva a la alteración de la estructura de la mucosa gastrointestinal. Lo anterior permite el paso de productos microbianos a circulación sistémica, provocando la activación de diferentes células del sistema inmune, favoreciendo al incremento de citoquinas proinflamatorias como IL-1 $\beta$, IL- 6 y TNF- $\alpha$, entre otras. B. Mucosa gastrointestinal tratada con probióticos/prebióticos: se observa un aumento en bacterias benéficas, que induce la producción de moco en la mucosa gastrointestinal, evitando la entrada de patógenos a esta. Adicionalmente, se incrementa el número de linfocitos T CD4 ${ }^{+}$y los niveles de IL-17 que promueve la proliferación de enterocitos, mejorando la integridad de la mucosa gastrointestinal. De esta manera, se previene el paso de productos microbianos a circulación sistémica, se disminuye el número de células activadas y por lo tanto la producción de citoquinas proinflamatorias.

De esta manera, se incrementa la muerte de células tanto infectadas como espectadoras, y el número de células susceptibles a la infección, promoviendo la replicación viral ${ }^{16}$. Adicionalmente, la hiperactivación inmune desencadena por la infección por el VIH-1 conduce al desarrollo de otras patologías, tales como vasculopatías y aterosclerosis, las cuales se producen por el efecto inflamatorio sobre las células endoteliales, y por sus efectos sobre las poblaciones de monocitos asociados con procesos aterogénicos como los monocitos $\mathrm{CD} 14^{+} \mathrm{CD} 16^{+17,18}$.

Finalmente, durante la fase crónica se da una destrucción de otras subpoblaciones de LT-CD4 ${ }^{+}$ como las células vírgenes y de memoria central, comprometiendo aun más la inmunidad ${ }^{4}$. Es de resaltar que la frecuencia y función de los LT difícilmente se reconstituyen, ya que durante la fase crónica se incrementa la producción de TGF- $\beta$ en el timo, debido a la destrucción tisular, lo que 
conlleva a la producción de colágeno, fibrosis del tejido y disminución de la función del órgano ${ }^{19}$. Todos estos procesos llevan a la pérdida del control de la infección y al desarrollo del SIDA².

\section{Probióticos, prebióticos y terapia simbiótica}

A principios del siglo XX se descubrieron microorganismos no patógenos que ejercían una influencia positiva en el hospedero, los cuales se denominaron "bacterias benéficas" . Según la Organización Mundial de la Salud, los probióticos mejoran la función de la barrera intestinal, promoviendo el crecimiento de bacterias benéficas y la proliferación de células epiteliales ${ }^{9}$. Microorganismos como Lactobacillus spp., Bifidobacterium spp. y Escherichia coli cepa Nissle son probióticos usados en el tratamiento de enfermedades como diarrea infecciosa, enfermedades inflamatorias intestinales, enterocolitis necrotizante, intolerancia a la lactosa y gastroenteritis viral ${ }^{20}$. Se ha demostrado que previenen la adhesión y colonización de patógenos y toxinas, induciendo péptidos antimicrobianos y favoreciendo la regulación de la respuesta inmune $^{21}$. La mayoría de investigaciones realizadas sobre probióticos han demostrado que esta terapia es segura y no genera efectos secundarios ${ }^{22}$.

Por otra parte, los prebióticos se caracterizan por ser alimentos biológicamente activos como carbohidratos, los cuales son fermentados por bacterias intestinales. Los metabolitos resultantes tienen un efecto benéfico en el GALT ${ }^{10}$. El principal mecanismo de acción de estos compuestos es controlar la disbiosis bacteriana en el tracto gastrointestinal, induciendo el crecimiento de bacterias benéficas como la Bifidobacterium spp. y Lactobacillus sop. y previniendo la unión de bacterias patógenas a células epiteliales ${ }^{23}$; además, se ha observado que los prebióticos pueden inducir la proliferación y conservación de las células epiteliales, fortaleciendo la integridad de la mucosa gastrointestinal ${ }^{24}$. De hecho, se ha reportado un efecto benéfico de los prebióticos en el cáncer colorrectal $^{24}$, la colitis, el estreñimiento y la enfermedad de $\mathrm{Crohn}^{25}$. Entre los prebióticos más utilizados se encuentran la inulina, presente en raíces, tubérculos y rizomas de plantas; los fructooligosacáridos (FOS), presentes principalmente en el banano, la cebolla y el trigo; los galactooligosacáridos (GOS), que se encuentran en derivados de la leche; y las fibras solubles ${ }^{26}$.

\section{Modulación de la respuesta inmune}

Como se mencionó anteriormente, estos compuestos favorecen la estructura y función de la mucosa gastrointestinal, en donde existe una estrecha relación entre el sistema inmune y la microbiota, que es crucial para la homeostasis del hospedero ${ }^{26}$. No obstante, existen muchos factores que pueden modular la microbiota intestinal promoviendo la alteración del sistema inmune.

Estudios previos han demostrado que el uso de probióticos/prebióticos puede inhibir o inducir una respuesta inflamatoria dependiendo del tipo de microorganismo o compuesto utilizado ${ }^{27}$. Las células mononucleares de sangre periférica (PBMC) tratadas con Lactobacillus sakei y Escherichia coli Nissle aumentan la expresión de CD69 y CD25 y de citoquinas proinflamatorias como IL- $1 \beta$, IL-6, TNF- $\alpha$ y GM-CSF en comparación con PBMC tratados únicamente con lipopolisacáridos (LPS ${ }^{28}$. Asimismo, algunas especies de probióticos mejoran la actividad de los linfocitos Th17 e inducen una respuesta tipo Th1, favoreciendo la inmunidad celular ${ }^{29}$. No obstante, se ha demostrado que el uso de probióticos puede aumentar la frecuencia de LT reguladores e inducir la producción de IL-10 $0^{30}$, además de regular negativamente la secreción de citoquinas proinflamatorias en PBMC de pacientes con colitis ulcerativa y síndrome de fatiga crónica ${ }^{31}$.

Los probióticos favorecen la conservación de la estructura, integridad y función de la barrera epitelial mediante varios mecanismos: i) mejorando las uniones estrechas entre las células epiteliales, a través de la activación del receptor de crecimiento epitelial de enterocitos (EGF-R ${ }^{32}$; ii) aumentando la liberación de mucinas y anticuerpos $\operatorname{IgA}^{33,34}$; iii) inhibiendo la respuesta citotóxica mediada por linfocitos intraepiteliales ${ }^{35}$; iv) incrementado la producción de bacteriocinas y defensinas ${ }^{36,37}$; v) incrementando la citotoxicidad de las células $\mathrm{NK}^{38}$; vi) induciendo la óxido nítrico sintasa en macrófagos que promueve un incremento de receptores tipo Toll y el FegammaRII ${ }^{39}$; vii) aumentando la producción de IL- $10^{30} ; \mathrm{y}$ viii) induciendo la producción de SOCS1, la cual inhibe la vía de señalización del NF- $\kappa \mathrm{B}$, reduciendo citoquinas proinflamatorias como la IL- $1 \beta$ y TNF- $\alpha^{40}$.

Por su parte, los prebióticos también tienen un papel importante en la modulación de la respuesta inmune, ya que su fermentación induce la sínte- 
sis de metabolitos producidos por la microbiota intestinal, como los ácidos grasos de cadena corta (AGCC), que se caracterizan por ejercer diversos efectos en la estructura e inmunidad de la mucosa gastrointestinal. Entre estos se encuentran: i) la modulación transcripcional de genes involucrados con la respuesta inmune, induciendo la expresión de histonas deacetilasas ${ }^{41}$; ii) la regulación en la producción de citoquinas proinflamatorias y antiinflamatorias; y iii) el mejoramiento de la integridad de la barrera epitelial intestinal, induciendo la expresión de la proteína quinasa activada por AMP que promueve las uniones estrechas intercelulares ${ }^{42}$. El butirato es uno de los AGCC más estudiados, debido a que es la mayor fuente de energía de las células epiteliales intestinales ${ }^{26}$. Este compuesto promueve la respuesta $T h 17^{43}$ y aumenta la frecuencia de LT reguladores, regulando negativamente la producción de IFN- $\gamma$ e inhibiendo la activación del factor de transcripción STAT1 en líneas celulares de carcinoma colateral $(\text { HTC116 })^{44}$. Otros metabolitos provenientes de los prebióticos son el acetato y el propionato, los cuales inducen la expresión de IL-10 $0^{45}$. Cada uno de los AGCC provenientes de los prebióticos poseen receptores anclados en la membrana celular para su reconocimiento; se ha demostrado la participación de los receptores GRP41 del butirato y el GP43 del propionato en la modulación de la respuesta inmune $e^{46}$. La histamina, otro metabolito proveniente de los prebióticos, disminuye la secreción de citoquinas proinflamatorias como TNF- $\alpha$ y aumenta la producción de IL-10 en células dendríticas estimuladas con $\mathrm{LPS}^{47}$. Adicionalmente, los prebióticos tienen la capacidad de inducir la expresión de péptidos antimicrobianos como la catelicidina en líneas celulares epiteliales ${ }^{48}$.

Estas evidencias sugieren que los probióticos/ prebióticos tiene un papel dual en la respuesta inmune de GALT, dependiendo de la cepa bacteriana o de la dieta alimenticia que se seleccione. Sin embargo, no se sabe con exactitud que vías y que componentes definen la respuesta que estos compuestos inducen.

\section{Efectos de los probióticos, prebióticos y terapia simbiótica en pacientes infectados con VIH-1}

Como se mencionó anteriormente, la TAR tiene un efecto mínimo en la restauración de la integridad estructural y funcional de la mucosa gastrointestinal y, por ende, en modular la activación inmune ${ }^{6}$. De hecho, se ha demostrado que pacientes que reciben TAR por más de 5 años, exhiben un alto porcentaje de LT-CD8 ${ }^{+} \mathrm{CD} 38^{+}$ y HLA-DR ${ }^{+}$y niveles altos de productos microbianos en circulación sistémica ${ }^{49}$; además, se ha demostrado que la pérdida masiva de enterocitos y de LT-CD4 $4^{+}$en la mucosa gastrointestinal lleva a una mala absorción de la $\mathrm{TAR}^{50}$. Estos hallazgos resaltan la importancia de buscar alternativas terapéuticas complementarias que mejoren la integridad de la mucosa gastrointestinal.

El suministro de probióticos en pacientes infectados con el VIH-1 ha demostrado mejorar la integridad de la mucosa gastrointestinal, fortaleciendo las uniones estrechas entre células epiteliales, lo que reduce los niveles de CD14s, proteína unidora de LPS (LBP), citoquinas proinflamatorias y LT activados, y aumenta los LT$\mathrm{CD}^{+}$en sangre ${ }^{7,51-54}$. Además de estos efectos sobre el sistema inmune, el uso de probióticos también disminuye los síntomas gastrointestinales en pacientes con VIH-1, como la diarrea ${ }^{55}$.

En contraste, algunos estudios han señalado que cuando los probióticos son administrados en yogurt, el efecto que se observa sobre los parámetros inmunes puede ser debido principalmente a los micronutrientes contenidos en bebidas lácteas ${ }^{56}$. Sin embargo, otros estudios mostraron que la ingesta de yogurt sin probióticos no parece tener un efecto sobre la recuperación de LT-CD4 ${ }^{+} \mathrm{O}$ sobre las manifestaciones gastrointestinales como la diarrea $^{57}$. Por otra parte, algunos estudios con probióticos no muestran ningún efecto en pacientes infectados con VIH-1 $1^{58}$, sugiriendo la importancia de realizar estudios adicionales en este campo que permita definir el potencial uso terapéutico que los probióticos/prebióticos puedan tener en la infección por el VIH-1.

En cuanto a la seguridad del tratamiento con probióticos/prebióticos, la mayoría de los estudios no han reportado efectos secundarios en pacientes infectados con VIH- ${ }^{58}$. No obstante, un estudio reportó que el suministro de probióticos en pacientes en fase SIDA favorece el desarrollo de bacteriemia por Lactobacillus acidophilus ${ }^{59}$, lo que indica que el eventual uso de probióticos en pacientes infectados debe hacerse bajo un estricto seguimiento clínico y en pacientes que no presenten un marcado deterioro inmunológico. 
A pesar de que los estudios con prebióticos en pacientes infectados son pocos, su suministro mejora la microbiota intestinal, promoviendo bacterias benéficas como Latobacillus spp. y Bifidobacterium spp.; además, reducen la translocación de productos microbianos a la circulación sistémica, aumentan la actividad citotóxica de las células NK y disminuyen la activación de LT-CD $4^{+8}$.

La terapia simbiótica o terapia combinada con probióticos y prebióticos ha tenido un gran impacto sobre la integridad y función de la mucosa gastrointestinal en pacientes infectados con VIH-1, en comparación con el uso de probióticos o prebióticos en forma independiente ${ }^{60}$. El suministro de la terapia simbiótica mejora la integridad estructural de la mucosa gastrointestinal, aumentando la carga bacteriana benéfica y reduciendo el paso de productos microbianos como el RNA $16 \mathrm{~s}$ a circulación sistémica ${ }^{11,61}$. Igualmente, el suministro de la terapia simbiótica promueve la recuperación de LT-CD4 en sangre y disminuye la respuesta inflamatoria, particularmente la producción de IL-6, sin generar efectos adversos ${ }^{60,61}$.

Cabe anotar que el uso de la terapia simbiótica (por ejemplo una mezcla de Lactobacillus spp. con inulina) puede tener también un efecto potencial en la reducción del riesgo de adquirir la infección por el VIH-1, ya que potencia la flora vaginal y evita infecciones, como la vaginosis bacteriana, que se han asociado con el incremento en la susceptibilidad del VIH- $1^{62}$.

Por otra parte, el impacto potencial de la terapia simbiótica en la infección por el VIH-1 se ha demostrado en modelos animales de macacos infectados con el virus de la inmunodeficiencia simiana, un virus homólogo del VIH-1. En este modelo se observó que en los animales tratados con simbióticos (VSL\#3 e inulina) hubo una disminución en la expresión de CD38 y HLA-DR en LT comparado con el placebo, además de un incremento en la expresión de genes relacionados con células presentadoras de antígeno y en la actividad polifuncional de los linfocitos Th17, lo que sugiere un rol importante en el restablecimiento del GALT ${ }^{29}$.

Finalmente, en la Tabla 1 se resumen los ensayos clínicos más importantes reportados a la fecha relacionados con el impacto que tiene la suplementación con prebióticos y probióticos o simbióticos en la evolución clínica de los

\section{Tabla 1. Ensayos clínicos en pacientes infectados con VIH-1 tratados con suplementos} prebióticos, probióticos o simbióticos

\begin{tabular}{|c|c|c|c|}
\hline $\begin{array}{l}\text { Autores } \\
\text { (referencia) }\end{array}$ & Población de estudio* & $\begin{array}{c}\text { Tipo de } \\
\text { suplementación }\end{array}$ & Resultados \\
\hline $\mathrm{d}^{\prime}$ Ettorre, G. et al $\left.\right|^{51}$ & $\begin{array}{l}\text { Grupo tratado: } \mathrm{n}=20 \\
\text { Carga viral: }<50 \text { copias } / \mathrm{mL} \\
\text { Recuento de } \mathrm{LT} \text { CD4 } 4^{+}: 542 \mathrm{cell} / \mu \mathrm{L} \\
\text { Grupo placebo: individuos sanos }\end{array}$ & $\begin{array}{l}\text { Streptoccocus spp } \\
\text { Termophilus } \\
\text { Bifidobacterium spp } \\
\text { Lactobacillus spp }\end{array}$ & $\begin{array}{l}\text { Incremento en el recuento } \\
\text { de LT CD4 } \\
\text { Disminución de LT CD4+ } \\
\text { activados. } \\
\text { Disminución de la proteína } \\
\text { unión a lipolisacáridos (LBP) } \\
\text { y de la proteína C reactiva } \\
\text { (PCR) en plasma }\end{array}$ \\
\hline $\begin{array}{l}\text { Villar-García, M. } \\
\text { et al }\end{array}$ & $\begin{array}{l}\text { Grupo tratado: } n=22 \\
\text { Carga viral: }<50 \text { copias } / \mathrm{mL} \\
\text { Recuento de } \mathrm{LT} C D 4^{+}: 220-427 \text { cell } / \mu \mathrm{L} \\
\text { Grupo placebo: } n=22 \\
\text { Carga viral: }<50 \text { copias } / \mathrm{mL} \\
\text { Recuento de } \mathrm{LT} C D 4^{+}: 207-503 \text { cell } / \mu \mathrm{L}\end{array}$ & $\begin{array}{l}\text { Probióticos: } \\
\text { Saccharomyces boulardii } \\
\text { Suministrados durante } \\
12 \text { semanas }\end{array}$ & $\begin{array}{l}\text { Disminución de IL- } 6 \text { y de la } \\
\text { LBP en plasma }\end{array}$ \\
\hline $\begin{array}{l}\text { Irvine, Stephanie L. } \\
\text { et al }{ }^{52}\end{array}$ & $\begin{array}{l}\text { Grupo tratado: } n=68 \\
\text { Recuento de } \mathrm{LT} C D 4^{+}: 366 \text { cell/ } \mu \mathrm{L} \\
\text { Grupo placebo: } n=82 \\
\text { Recuento de } \mathrm{LT} C D 4^{+}: 366 \mathrm{cell} / \mu \mathrm{L}\end{array}$ & $\begin{array}{l}\text { Probióticos: } \\
\text { Lactobacillus rhamnosus } \\
\text { Suministradosdurante } \\
12 \text { semanas }\end{array}$ & $\begin{array}{l}\text { Incremento en el recuento } \\
\text { de LT CD4 }{ }^{+}\end{array}$ \\
\hline
\end{tabular}


Tabla 1. Continuación

\begin{tabular}{|c|c|c|c|}
\hline Trois, Livia. et al ${ }^{53}$ & $\begin{array}{l}\text { Grupo tratado: } n=38 \\
\text { Recuento de } L T C D 4^{+}: 528-962 \mathrm{cell} / \mu \mathrm{L} \\
\text { Grupo placebo: } \mathrm{n}=39 \\
\text { Recuento de } \mathrm{LT} C D 4^{+}: 337-821 \mathrm{cell} / \mu \mathrm{L}\end{array}$ & $\begin{array}{l}\text { Probióticos: } \\
\text { Bifidobacterium bifidum } \\
\text { y Streptococcus } \\
\text { thermofilus } \\
\text { Suministrados durante } 4 \\
\text { semanas }\end{array}$ & $\begin{array}{l}\text { Incremento en el recuento } \\
\text { de } \mathrm{LT} \mathrm{CD4}^{+}\end{array}$ \\
\hline $\begin{array}{l}\text { Anukam, } \\
\text { Kingsley C. }{ }^{57}\end{array}$ & $\begin{array}{l}\text { Grupo tratado: } \mathrm{n}=12 \\
\text { Recuento de } \mathrm{LT} C D 4^{+}: 359 \mathrm{cell} / \mu \mathrm{L} \\
\text { Grupo placebo: } \mathrm{n}=12 \\
\text { Recuento de } \mathrm{LT} C D 4^{+}: 347 \mathrm{cell} / \mu \mathrm{L}\end{array}$ & $\begin{array}{l}\text { Probióticos: } \\
\text { Lactobacillus rhamnosus } \\
\text { y Lactobacillus reuteri } \\
\text { Suministrados durante } \\
15 \text { días }\end{array}$ & $\begin{array}{l}\text { Incremento en el recuento } \\
\text { de LT CD4 }{ }^{+} \text {y disminución en } \\
\text { la frecuencia de las diarreas }\end{array}$ \\
\hline Gori, A. et al ${ }^{8}$ & $\begin{array}{l}\text { Grupo tratado: } \mathrm{n}=36 \\
\text { Recuento de } \mathrm{LT} C D 4^{+}: 536 \mathrm{cell} / \mu \mathrm{L} \\
\text { Grupo placebo: } \mathrm{n}=19 \\
\text { Recuento de } \mathrm{LT} C D 4^{+}: 502 \mathrm{cell} / \mu \mathrm{L}\end{array}$ & $\begin{array}{l}\text { Prebióticos: } \\
\text { Galactooligosacáridos, } \\
\text { fructooligosacáridos y } \\
\text { oligosacáridos ácidos } \\
\text { Suministrados durante } \\
12 \text { semanas }\end{array}$ & $\begin{array}{l}\text { Reducción de CD14s en } \\
\text { plasma y de la activación de } \\
\text { los LT CD4 }{ }^{+} \text {, e incremento } \\
\text { en la actividad de las células } \\
\text { NK }\end{array}$ \\
\hline $\begin{array}{l}\text { González-Hernández, } \\
\text { LA. et al }{ }^{60}\end{array}$ & 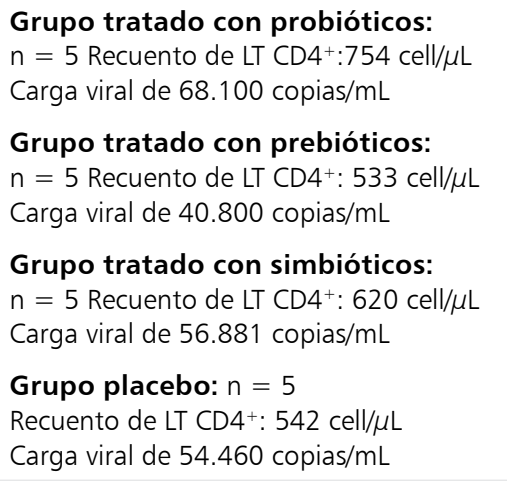 & $\begin{array}{l}\text { Probióticos: } \\
\text { Lactobacillus rhamnosus } \\
\text { y Bifidobacterium lactis. } \\
\text { Prebióticos: } \\
\text { Agave tequilana } \\
\text { Simbióticos: } \\
\text { Combinación de probió- } \\
\text { ticos y prebióticos } \\
\text { Suministrados durante } \\
16 \text { semanas }\end{array}$ & $\begin{array}{l}\text { Incremento en el recuento } \\
\text { de } L T C D 4^{+} \text {y disminución de } \\
\text { IL-6 y de ADN bacteriano en } \\
\text { plasma }\end{array}$ \\
\hline Shunter, M. et al ${ }^{11}$ & $\begin{array}{l}\text { Grupo tratado con prebióticos: } \\
\mathrm{n}=13 \text { Recuento de } \mathrm{LT} C \mathrm{CD} 4^{+}: 588 \text { cell/ } \mu \mathrm{L} \\
\text { Carga viral }<50 \text { copias } / \mathrm{mL} \\
\text { Grupo tratado con simbióticos: } \\
\mathrm{n}=14 \text { Recuento de } \mathrm{LT} C D 4^{+}: 685 \text { cell/ } \mu \mathrm{L} \\
\text { Carga viral }<50 \text { copias } / \mathrm{mL}\end{array}$ & $\begin{array}{l}\text { Prebióticos: } \\
\text { Betaglucano, inulina, } \\
\text { pectina y almidón } \\
\text { Probióticos: } \\
\text { Pediococcus pentosaceu, } \\
\text { Leuconostoc mesen- } \\
\text { teroides, Lactobacillus } \\
\text { paracasei y Lactobacillus } \\
\text { plantarun } \\
\text { Simbióticos: } \\
\text { Combinación de probió- } \\
\text { ticos y prebióticos } \\
\text { Suministrados durante } 4 \\
\text { semanas }\end{array}$ & $\begin{array}{l}\text { Mejoramiento de la flora } \\
\text { intestinal y disminución de } \\
\text { la activación de los LT CD4 }\end{array}$ \\
\hline Hummelen, R. et al $\left.\right|^{54}$ & $\begin{array}{l}\text { Grupo tratado con probióticos: } \\
\mathrm{n}=24 \text { Recuento de } \mathrm{LT} C D 4^{+}: 350 \mathrm{cell} / \mu \mathrm{L} \\
\text { Grupo placebo: } \mathrm{n}=29 \\
\text { Recuento de } \mathrm{LT} C D 4^{+}: 350 \mathrm{cell} / \mu \mathrm{L}\end{array}$ & $\begin{array}{l}\text { Probióticos: } \\
\text { Lactobacillus rhamnosus } \\
\text { y Lactobacillus reuteri } \\
\text { Suministrados durante } \\
25 \text { semanas. }\end{array}$ & $\begin{array}{l}\text { Incremento en el recuento } \\
\text { de } L T C D 4^{+}\end{array}$ \\
\hline
\end{tabular}

\footnotetext{
* En todos los estudios, tanto el grupo tratado como el placebo, estaban conformados por pacientes infectados con VIH-1.
} 
pacientes infectados con VIH-1. Entre los resultados más relevantes de estos ensayos clínicos se ha observado una disminución de los síntomas gastrointestinales como diarrea y náuseas ${ }^{57}$; un crecimiento de bacterias benéficas como Lactobacillus plantarum, Pedioococus pentosauceus que induce un mejoramiento en la microflora intestinal ${ }^{11}$; recuperación de la integridad de la barrera epitelial ${ }^{8}$; y un incremento en el recuento de LT-CD4 ${ }^{+60}$. Cabe resaltar que a la fecha en el sitio web oficial de ensayos clínicos del Instituto Nacional de Salud de Estados Unidos de Norteamérica existen aproximadamente 10 estudios registrados, los cuales están enfocados en evaluar si estos suplementos disminuyen las alteraciones gastrointestinales provocadas por el VIH-1 y su capacidad para potenciar la respuesta al tratamiento antirretroviral. Estas investigaciones dan cuenta del creciente interés científico que existe alrededor del uso de probióticos/prebióticos en los pacientes infectados con VIH-1, y aunque su uso no está actualmente aprobado para el tratamiento de los pacientes infectados, dada la evidencia clínica y de laboratorio, estudios futuros en cohortes más grandes y con mayor tiempo de seguimiento, permitirán establecer su uso como tratamiento complementario a la terapia antirretroviral.

\section{Conclusiones}

Los probióticos/prebióticos tienen la capacidad de modular la repuesta inmune y de mejorar la integridad de la barrera epitelial, manteniendo la homeostasis del GALT, por lo que pueden tener un potencial uso en los pacientes infectados con VIH-1, dada la magnitud del daño de la mucosa intestinal que experimentan estos pacientes. Los estudios disponibles en este campo demuestran que la terapia con probióticos/prebióticos puede reducir el perfil inflamatorio, incrementar el recuento de LTCD4+ y reducir los niveles de compuestos microbianos en sangre periférica de pacientes infectados con VIH-1. Sin embargo, debido a que algunos ensayos clínicos no han mostrado efectos significativos o incluso, han encontrado efectos adversos posteriores a la administración de probióticos, se requieren estudios adicionales en este campo que permitan establecer la aplicabilidad de la terapia con probióticos/prebióticos, como complemento de la TAR, o incluso como alternativa para prevenir la infección por el VIH-1.
Agradecimientos: Los autores agradecemos a la Universidad de Antioquia UdeA, al CODI-Universidad de Antioquia convocatoria programática Ciencias de la Salud 2014-2015 y a la Corporación Universitaria Remington (Convocatoria interna de proyectos año 2015).

\section{Referencias}

1. UNAIDS. Global report. AIDS epidemic update. 2015.

2. Levy J. HIV and the Pathogenesis of AIDS, 3rd Edition. ASM Press; 2007. 644-700 p.

3. Borrow P. Innate immunity in acute HIV-1 infection. Curr Opin HIV AIDS 2012; 6 (5): 353-63.

4. Levy J. HIV pathogenesis: 25 years of progress and persistent challenges. AIDS 2009; 23 (2): 147-60.

5. Abad-Fernández $M$, Vallejo A, Hernández-Novoa B, Díaz L, Gutiérrez C, Madrid N, et al. Correlation Between Different Methods to Measure Microbial Translocation and Its Association With Immune Activation in Long-Term Suppressed HIV-1 - Infected Individuals. J Acquir Immune Defic Syndr 2013; 64 (2): 149-53.

6. Taborda N, Rugeles M, Montoya C. Spontaneous Control of HIV Replication, but not HAART-Induced Viral Suppression, Is Associated With Lower Activation of Immune Cells. J Acquir Immune Defic Syndr 2014; 66 (4): 365-9.

7. Villar-García J, Hernández J, Güerri-Fernández R, González A, Lerma E, Guelar A, et al. Effect of probiotics (Saccharomyces boulardii) on microbial translocation and inflammation in HIV-treated patients: a double-blind, randomized, placebo-controlled trial. J Acquir Immune Defic Syndr 2014; 68 (3): 256-63.

8. Gori A, Rizzardini G, Van't Land B, Amor K, van Schaik J, Torti C, et al. Specific prebiotics modulate gut microbiota and immune activation in HAART-naive HIV-infected adults: results of the "COPA" pilot randomized trial. Mucosal Immunol 2011; 4 (5): 554-63.

9. Behnsen J, Deriu E, Sassone-Corsi M, Raffatellu M. Probiotics: properties, examples, and specific applications. Cold Spring Harb Perspect Med 2013; 3 (3): 1-15.

10. Manning T, Gibson G. Prebiotics. Best Pract Res Clin Gastroenterol 2004; 18 (2): 287-98.

11. Schunter M, Chu H, Hayes T, McConnell D, Crawford S, Luciw P, et al. Randomized pilot trial of a synbiotic dietary supplement in chronic HIV-1 infection. BMC Complement Altern Med 2012; 12 (84): 1-15.

12. Shacklett B, Anton P. HIV Infection and Gut Mucosal Immune Function: Updates on Pathogenesis with Impli- 
cations for Management and Intervention. Curr Infect Dis Rep 2010; 12 (1): 19-27.

13. Doitsh G, Galloway N, Geng X, Yang Z, Monroe KM, Zepeda O, et al. Cell death by pyroptosis drives CD4 T-cell depletion in HIV-1 infection. Nature 2014; 505 (7484): 509-14.

14. Marchetti G, Tincati C, Silvestri G. Microbial translocation in the pathogenesis of HIV infection and AIDS. Clin Microbiol Rev 2013; 26 (1): 2-18.

15. Khaitan A. Revisiting Immune Exhaustion During HIV Infection. Curr HIV/AIDS Rep 2012; 8 (1): 4-11.

16. Brenchley J, Price D, Douek D. HIV disease: fallout from a mucosal catastrophe? Nat Immunol 2006; 7 (3): 235-9.

17. Petroni A, Deluchi G, Larran G, Alonso B, Benetucci J. Viral load and disease progression as responsible for endothelial activation and/or injury in human immunodeficiency virus-1-infected patients. Blood Coagul Fibrinolysis 2003; 14 (1): 15-8.

18. Funderburg N, Zidar D, Shive C, Lioi A, Mudd J, Musselwhite L, et al. Shared monocyte subset phenotypes in HIV-1 infection and in uninfected subjects with acute coronary syndrome. Blood 2012; 120 (23): 4599-608.

19. Estes J, Wietgrefe S, Schacker T, Southern P, Beilman G, Reilly C, et al. Simian Immunodeficiency Virus-Induced Lymphatic Tissue Fibrosis Is Mediated by Transforming Growth Factor b 1-Positive Regulatory T Cells and Begins in Early Infection. J Infect Dis 2007; 195 (1): 551-61.

20. Gareau M, Sherman P, Walker W. Probiotics and the gut microbiota in intestinal health and disease. Nat Rev Gastroenterol Hepatol 2010; 7 (9): 503-14.

21. Kechagia M, Basoulis D, Konstantopoulou S, Dimitriadi D, Gyftopoulou K, Skarmoutsou N, et al. Health Benefitd of Probiotics: A review. ISRN Nutr 2013; 2013: 1-7.

22. Sanders M, Akkermans L, Haller D, Hammerman C, Heimbach J, Hörmannsperger G, et al. Safety assessment of probiotics for human use. Gut Microbes 2010; 1 (3): 164-85.

23. Shoaf K, Mulvey G, Armstrong G, Hutkins R. Prebiotic Galactooligosaccharides Reduce Adherence of Enteropathogenic Escherichia coli to Tissue Culture Cells. Infect Immun 2006; 74 (12): 6920-8.

24. Commane D, Shortt C, Silvi S, Cresci A, Hughes R, Rowland I. Effects of fermentation products of pro- and prebiotics on trans-epithelial electrical resistance in an in vitro model of the colon. Nutr Cancer 2005; 51 (1): 102-9.

25. Guarner F. Prebiotics in inflammatory bowel diseases. Br J Nutr 2007; 98 Suppl 1: S85-9.

26. Vieira A, Teixeira M, Martins F. The role of probiotics and prebiotics in inducing gut immunity. Front Immunol 2013; 4 (445): 1-12.

27. Hardy H, Harris J, Lyon E, Beal J, Foey A. Probiotics, prebiotics and immunomodulation of gut mucosal defences: homeostasis and immunopathology. Nutrients 2013; 5 (6): 1869-912.

28. Dong H, Rowland I, Yaqoob P. Comparative effects of six probiotic strains on immune function in vitro. $\mathrm{Br} \mathrm{J}$ Nutr 2011; 108 (1): 459-70.

29. Klatt N, Canary LA, Sun X, Vinton CL, Funderburg N, Morcock D, et al. Probiotic/prebiotic supplementation of antiretrovirals improves gastrointestinal immunity in SIV-infected macaques. J Clin Invest 2013; 123 (2): 903-7.

30. Konieczna P, Groeger D, Ziegler M, Frei R, Ferstl R, Shanahan F, et al. Bifidobacterium infantis 35624 administration induces Foxp3 T regulatory cells in human peripheral blood: potential role for myeloid and plasmacytoid dendritic cells. Gut 2012; 61: 354-66.

31. Groeger D, O’Mahony L, Murphy E, Bourke J, Dinan T, Kiely B, et al. Bifidobacterium infantis 35624 modulates host inflammatory processes beyond the gut. Gut Microbes 2013; 4 (4): 325-39.

32. Resta-Lenert S, Barrett K. Live probiotics protect intestinal epithelial cells from the effects of infection with enteroinvasive Escherichia coli (EIEC). Gut 2003; 52: 988-97.

33. Wang L, Cao H, Liu L, Wang B, Walker W, Acra SA, et al. Activation of epidermal growth factor receptor mediates mucin production stimulated by $\mathrm{p} 40$, a Lactobacillus rhamnosus GG-derived protein. J Biol Chem 2014; 289 (29): 20234-44.

34. Rautava S, Arvilommi H, Isolauri E. Specific probiotics in enhancing maturation of IgA responses in formula-fed infants. Pediatr Res 2006; 60 (2): 221-4.

35. Roselli M, Finamore A, Nuccitelli S, Carnevali P, Brigidi P, Vitali B, et al. Prevention of TNBS-induced colitis by different Lactobacillus and Bifidobacterium strains is associated with an expansion of $\mathrm{T}$ and regulatory $\mathrm{T}$ cells of intestinal intraepithelial lymphocytes. Inflamm Bowel Dis 2009; 15 (10): 1526-36.

36. Möndel M, Schroeder B, Zimmermann K, Huber H, Nuding S, Beisner J, et al. Probiotic E. coli treatment mediates antimicrobial human beta-defensin synthesis and fecal excretion in humans. Mucosal Immunol 2009; 2 (2): 166-72.

37. Zschüttig A, Zimmermann K, Blom J, Goesmann A, Pöhlmann C, Gunzer F. Identification and characterization of microcin $\mathrm{S}$, a new antibacterial peptide produced by probiotic Escherichia coli G3/10. PLoS One. 2012; 7 (3): 1-9. 
38. Sheih Y, Chiang B, Wang L, Liao C, Gill H. Systemic immunity-enhancing effects in healthy subjects following dietary consumption of the lactic acid bacterium Lactobacillus rhamnosus HN001. J Am Coll Nutr 2001; 20 (2 Suppl): 149-56.

39. Kengatharan M, De Kimpe SJ, Thiemermann C. Analysis of the signal transduction in the induction of nitric oxide synthase by lipoteichoic acid in macrophages. $\mathrm{Br}$ J Pharmacol 1996; 117 (6): 1163-70.

40. Okada Y, Tsuzuki Y, Hokari R, Komoto S, Kurihara C, Kawaguchi A, et al. Anti-inflammatory effects of the genus Bifidobacterium on macrophages by modification of phospho-IkB and SOCS gene expression. Int J Exp Pathol 2009; 90 (2): 131-40.

41. Dangond F, Gullans S. Differential expression of human histone deacetylase mRNAs in response to immune cell apoptosis induction by trichostatin A and butyrate. Biochem Biophys Res Commun 1998; 247 (3): 833-7.

42. Peng L, Li Z-R, Green R, Holzman I, Lin J. Butyrate enhances the intestinal barrier by facilitating tight junction assembly via activation of AMP-activated protein kinase in Caco-2 cell monolayers. J Nutr 2009; 139 (9): 161925.

43. Berndt B, Zhang M, Owyang S, Cole TS, Wang T, Luther $\mathrm{J}$, et al. Butyrate increases IL-23 production by stimulated dendritic cells. AJP Gastrointest Liver Physiol 2012; 303 (12): 1384-92.

44. Klampfer L, Huang J, Sasazuki T, Shirasawa S, Augenlicht L. Inhibition of interferon gamma signaling by the short chain fatty acid butyrate. Mol Cancer Res 2003; 1 (11): 855-62.

45. Kiefer J, Beyer-Sehlmeyer G, Pool-Zobel B. Mixtures of SCFA, composed according to physiologically available concentrations in the gut lumen, modulate histone acetylation in human HT29 colon cancer cells. Br J Nutr 2006; 96: 803-10.

46. Maslowski K, Vieira A, Ng A, Kranich J, Sierro F, Yu D, et al. Regulation of inflammatory responses by gut microbiota and chemoattractan receptor GPR43. Nature. 2009;461(7268):1282-6.

47. Frei R, Ferstl R, Konieczna P, Ziegler M, Simon T, Rugeles $\mathrm{T}$, et al. Histamine receptor 2 modifies dendritic cell responses to microbial ligands. J Allergy Clin Immunol. Elsevier Ltd. 2013; 132 (1): 194-204.

48. Jiang W, Sunkara L, Zeng X, Deng Z, Myers S, Zhang G. Differential regulation of human cathelicidin LL-37 by free fatty acids and their analogs. Peptides. Elsevier Inc. 2013; 50: 129-38.

49. Zhang X, Hunt P, Hammer S, Cespedes M, Patterson K, Bosch R. Immune Activation While on Potent Antire- troviral Therapy Can Predict Subsequent CD4+ T-Cell Increases Through 15 Years of Treatment. HIV Clin Trials 2013; 14 (2): 61-7.

50. Gordon SN, Cervasi B, Odorizzi P, Silverman R, Aberra F, Ginsber G, et al. Disruption of Intestinal CD4+ T Cell Homeostasis Is a Key Marker of Systemic CD4+ T Cell Activation in HIV-Infected Individuals. J Immunol 2011; 185 (9): 5169-79.

51. D'Ettorre G, Ceccarelli G, Giustini N, Serafino S, Calantone N, De Girolamo G, et al. Probiotics reduce inflammation in antiretroviral treated, HIV-infected individuals: Results of the "Probio-HIV" clinical trial. PLoS One 2015; 10 (9): 1-15.

52. Irvine S, Hummelen R, Hekmat S, Looman CW, Habbema JD, Reid G. Probiotic yogurt consumption is associated with an increase of CD4 count among people living with HIV/AIDS. J Clin Gastroenterol 2010; 44 (9): 201-5.

53. Trois L, Cardoso E, Miura E. Use of probiotics in HIV-infected children: A randomized double-blind controlled study. J Trop Pediatr 2008; 54 (1): 19-24.

54. Hummelen R, Changalucha J, Butamanya NL, Koyama T, Cook A, Habbema JDF, et al. Effect of 25 weeks probiotic supplementation on immune function of HIV patients. Gut Microbes 2011; 2 (2): 80-5.

55. Guinane $\mathrm{S}$. The effectiveness of probiotics for managing diarrhoea in people with HIV infection: A critically appraised topic. HIV Med 2013; 14: 187-90.

56. Hemsworth JC, Hekmat S, Reid G. Micronutrient supplemented probiotic yogurt for HIV-infected adults taking HAART in London, Canada. Gut Microbes 2012; 3 (5): 414-9.

57. Anukam K, Osazuwa E, Osadolor H, Bruce A, Reid G. Yogurt containing probiotic Lactobacillus rhamnosus GR-1 and L. reuteri RC-14 helps resolve moderate diarrhea and increases CD4 count in HIV/AIDS patients. J Clin Gastroenterol 2008; 42 (3): 239-43.

58. Salminen M, Tynkkynen S, Rautelin H, Poussa T, Saxelin M, Ristola M, et al. The Efficacy and Safety of Probiotic Lactobacillus rhamnosus GG on Prolonged, Noninfectious Diarrhea in HIV Patients on Antiretroviral Therapy: A Randomized, Placebo-Controlled, Crossover Study. HIV Clin Trials 2004; 5 (4): 183-91.

59. Haghighat L, Crum-Cianflone N. The potential risks of probiotics among HIV-infected persons: Bacteraemia due to Lactobacillus acidophilus and review of the literature. Int J STD AIDS [Internet] 2015; 0 (0): 1-8. Available from: http://std.sagepub.com/lookup/ doi/10.1177/0956462415590725

60. González-Hernández L, Jave-Suárez L, Fafutis-Morris M, Montes-Salcedo K, Valle-Gutiérrez L, Campos-Loza 
A, et al. Synbiotic therapy decreases microbial translocation and inflammation and improves immunological status in HIV-infected patients: a double-blind randomized controlled pilot trial. Nutr J 2012; 11 (90): 1-8.

61. Van den Nieuwboer M, Brummer R, Guarner F, Morelli L, Cabana M, Claasen E. The administration of probio- tics and synbiotics in immune compromised adults: is it safe? Benef Microbes 2015; 6 (1): 3-17.

62. Schwiertz A, Knauf M, Hackei B, Mueller H-J. Effectiveness and Tolerability of a Synbiotic Vaginal Suppository for the Treatment of Bacterial Vaginosis. Gynecol Obstet 2015; 5 (2): 1-6. 